\title{
Tribological Aspects of Wheel-Rail Contact: A Review of Wear Mechanisms and Effective Factors on Rolling Contact Fatigue
}

\author{
Hesam Soleimani1 $^{1}$ (D) Majid Moavenian ${ }^{1}$
}

Received: 29 June 2017/Revised: 10 October 2017/ Accepted: 2 November 2017/Published online: 14 November 2017

(c) The Author(s) 2017. This article is an open access publication

\begin{abstract}
Nowadays, the railway is considered as a means of fast, aggregate and secure transportation. The issue of the rail and wheel contact is one of the most fundamental aspects in the railway system since inappropriate interactions create problems such as wear and a negative effect in the dynamic functioning of the train. In this research, we analyze one of the most important phenomenon in a railway system which is the contact of the rail and wheel. This review is done in the scope of the most fundamental deteriorating aspect of the rail and wheel system, the wear. The wear in the contact of objects along with its occurrence between the wheel and rail is also analyzed.
\end{abstract}

Keywords Wear · Wheel-rail contact - Railway system · Surface roughness - Transportation - Inappropriate interaction

\section{Introduction}

In the present century, transit and transportation in terms of loads and passengers are essential issues of human life and a large volume of air, territorial, sea and rail transportation is being performed every day. The railway system has been considered as a means of fast, aggregate and secure

Hesam Soleimani

Hesamsoleimani@gmail.com

Majid Moavenian

Moaven@um.ac.ir

1 Department of Mechanical Engineering, Ferdowsi University of Mashhad, Mashhad, Iran

Editor: Gary Barber transportation as well as a serious rival for air transportation in the fields of security and speed. The most significant advantages of railway transportation are lower energy consumption, aggregate transportation, higher security and environment preservation. The issue of the rail and wheel contact is one of the most fundamental aspects in the railway system, and the interaction of the wheel and rail in the railway transportation system has always been taken into consideration for many years. Studying the wear phenomenon between the rail and wheel has led to a design of the suspension system and wheel profile which is proportionate to the wear process because using the optimum wheel profile will lead to dynamic stability, comfort in expedition and security against emersion from the rail especially in arched paths [1-4].

The interaction of the rail and wheel and the resulting phenomena such as wear and noise are considered as very important issues in railway transportation which allocates considerable research activities in advanced railways in the world yearly since the inappropriate interaction of the rail and wheel has always brought about costly items such as extreme structure of the instruments and fractures of pavement and road bed of the lines and also automotive transportation and most importantly causes irreparable accidents. By analyzing the repair and maintenance railway costs worldwide, we found that a huge expedition is done in the field of purchase, change and installation of the rail and wheel in the railway industry every year $[5,6]$. The wheel has a special geometric form, and the geometric incompatibility of a wheel's profile with the geometric characteristics of the rail line could have negative circumstances such as extreme wear of the rail and wheel and dynamic instability of the railway transportation appliance, since the stability of the railway appliance and the passengers comfort is dependent on the wear of the rail and 
wheel [7]. Thus, it could be inferred that the compatibility of the rail and wheel's profile is the most vital factor in controlling the wear. The rolling contact of the rail and wheel will cause wearing of the rail and wheel profile and in return there will be phenomena such as negative effects in dynamic function of the train and comfort in traveling, the possibility of emersion from the line, permanent misshapes, reduction in the wheel longevity, reduction in security, reduction in the repairing period of the line and, as a result, a reduction in efficiency and an increase in costs [8]. Recognition and reduction in the mentioned phenomena require sufficient knowledge of the wheel and rail wear. Due to the solidity of the contact surfaces of the rail and wheel, small contact area and the heavy weight applied in railway cars, there is high stress that would lead to phenomena such as wear and fatigue of the rail and wheel.

The importance of the wearing issue in terms of security and financial aspects has made wear a significant issue in the railway industry. The studies regarding wearing of the rail and wheel in the rail industry began a half century ago because in the late 1960s there had been an increasing wheel wear. Moreover, the wear problem was taken into consideration from 1970 to 1996 as an important issue by railway researchers [9]. In these studies, speed and the load base of the railway appliances were introduced as the most important factors of wear in railway appliance wheels [10]. Friction and wear between two surfaces when these surfaces have rolling movements, while being loaded, are an inevitable consequence. Friction is an important factor in energy loss and wear is an important factor in material loss; thus, by reducing or controlling wear you can economize the material and energy use. To control and reduce the friction and the wear rate of two surfaces, there are preventive and controlling methods such as using different materials in the production of rail and pavement materials of the line, effective methods of lubrication, speed regulation and radial load used in different railways [5]. It must be noted that using the railway system in non-ideal conditions would cause the rail and the wheel to be worn and would reduce the functionality and security of the system. Studies that have been done using field measurements, using the byline materials, show that the wear between the wheel and rail especially in the flange area relies to a large extent on the bogie condition (axle) and its functionality [11].

The introduction of the rail and wheel could be separated into two periods. In the first period, the speed of the trains was relatively low and the rail and wheel contact was analyzed statically. Many of the research studies in this era led to a series of theories that were all based on the Hertz contact theory and would hypothesize that the contact area had an oval shape [7]. In 1926, the two-dimensional rolling theory with friction was introduced by Karter [12] to be used in railway appliances dynamics. Johnson and Vermoulen [13] have extended their theory to include an ideal surface with creep and without rotation. In this theory, the contact surface of the rolling parts was divided into two areas (slip and adhesion). Haling et al. [14] have introduced improvements for the approximate theory of oval contact with the net linear tripping. Kalker demonstrated a new approximate method that resembled Karters's model [15]. Moreover, Kalker [16] used numerical theories and methods based on the finite element method. Xia and Gave [17] demonstrated a model to analyze the side stability in the arch, using the recoil rate and the damping of the rail and its infrastructure. Zhandel [11] worked on the wear forecasting of the wheel in comparison with the results of field measurements. Telliskivi and Olofsson [18] used the Metallurgical point of view and the concept of wear number to obtain the wear amount of the line and rail. Diana and Brownie [19] analyzed the effects of the wear of the rail and wheel on dynamic characteristics. Braghin and Louis [20] investigated the wear amount of the wheel profile using a mathematical model. Ranger [21] analyzed the side stability of the wagon with high speed in the arches. Turner [22] used a disk on disk instrument to determine the effect of speed and the percentage of trip on the wear of rail and wheel.

The first level of wearing includes surface destruction, but in the following steps it could lead to friction, noise, unwanted heat and dimensional changes in different parts. These phenomena would interfere with the functionality of the products and could possibly lead to a disastrous failure. In this study, we will analyze the most important existing phenomenon which is the contact of the rail and wheel. This consultation is done in the scope of the most fundamental deteriorating aspect in the rail and wheel system, the wear. In this research, we will analyze the wear phenomenon in the contact of objects along with its interaction between the wheel and rail, and then, the effective factors of the wheel and rail are introduced.

\section{The Contact Surface of the Rail and Wheel}

An ideal sample design for the rail and wheel profiles is demonstrated in Fig. 1. There are three contact areas. The first area is for the motion of straight lines and the conical coefficient, which is defined as the ratio of half the difference between left and right wheel rolling radius of an axis to movement of transverse axis, is often designed from 0.15 to 0.2 for passenger trains. Higher values depending on the structure of bogies would cause dynamic instability, and lower levels will cause higher number of flange hits and faster increasing wear. The second area is for passing through the normal arcs and needs to have a conical 


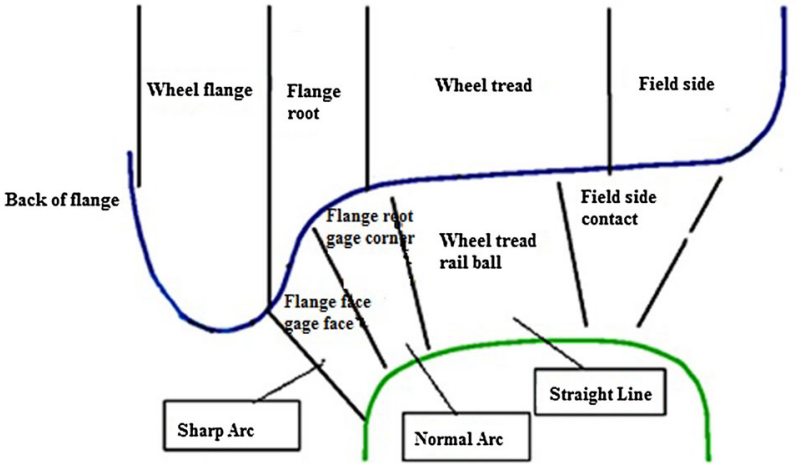

Fig. 1 Contact points of the rail and wheel in a variety of paths [23]

coefficient of $0.2-0.6$ in the region, while in the third area higher values are required [23].

In the absence of sidelong stimulations in straight lines, wheel and rail contact areas are shown in Fig. 1 and will generally be focused in the center of the wheel and the rail. In passing arch paths, the outer wheel of the front axle of a bogie is diverted to a greater extent to the flange rather than outer wheel of the back axle one.

Keeping all of the above general information, contact areas of the wheel and rail (Fig. 2) can be divided into three areas $[24,25]$.

\subsection{Contact Area A (The Central Rail and Profiles Crown Center)}

More frequently in straight lines and gentle arcs, the type of contact is rolling, as we have a little slip, and the wear is called vertical abrasion wear. The contact area can be characterized as follows [24]:

- Contact stress between wheel and rail is lower than in other areas.

- Longitudinal creep forces are larger compared to the side creep forces.

- Crown wheel depression occurs due to wear.

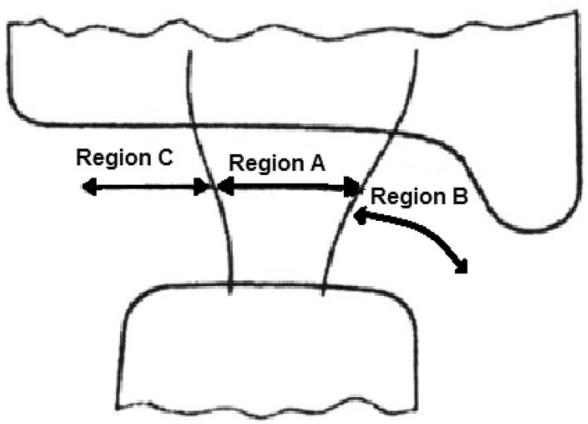

Fig. 2 Contact areas of rail and wheel [25]
Exfoliated skin of rail, rot, deformation and transverse and longitudinal cracks are the consequences of vertical wear in region $\mathrm{A}$.

\subsection{Contact in Area B (Contact Between the Inner Edge of the Track and Wheel Flange Arc)}

In sharp curves due to centrifugal forces, the contact is pure slip and abrasion wear is called side wear. Contact characteristics in this area can be mentioned as follows $[24,25]$ :

- High contact stresses.

- Wear of the inner surface of the outer arc rails.

- High side creep and sharp flange.

- This area is most important in determining the life of the wheels and rails.

In the contact area $\mathrm{B}$, there are three contact parts.

\subsubsection{Single Contact Point}

This type of contact is the worst contact condition of wheels and rails (Fig. 3). High contact stresses, due to focus of load on a small area of contact with high creep in this area, cause fatigue in the rolling contact of the inner side of the rail. This type of exposure can lead to wheel flange wear, too. This disaster results in an asymmetric grinding wheel in straight lines [24].

\subsubsection{Two Contact Point}

In this contact mode, the wear of flange is severe enough that the lubricant layer is eliminated in the arcs and metalto-metal contact occurs (Fig. 4). The internal side rail in this contact is worn intensively [24].

\subsubsection{Conformal Contact}

This type of contact can be seen with the simultaneous wear of the wheel flange and inner side of the rail and contact of the two profiles in curved lines (Fig. 5). In this

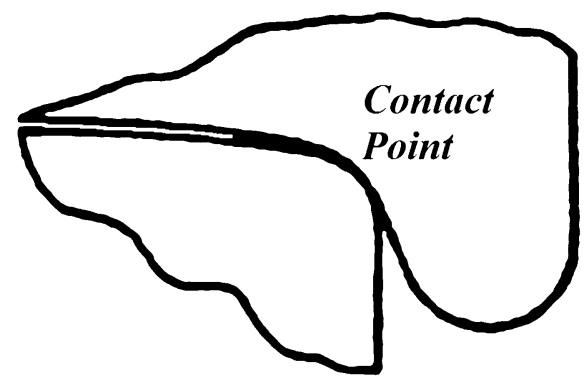

Fig. 3 Single contact point schematic [24] 


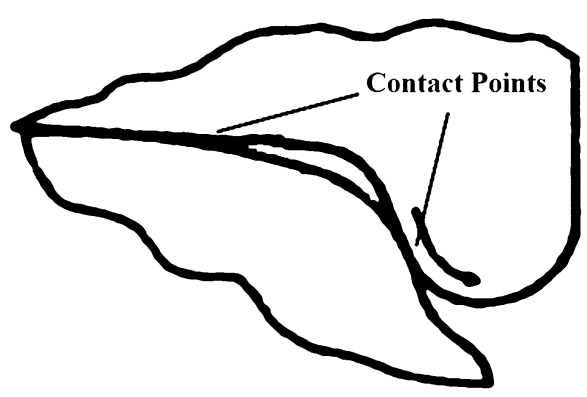

Fig. 4 Schematic of two contact points [24]

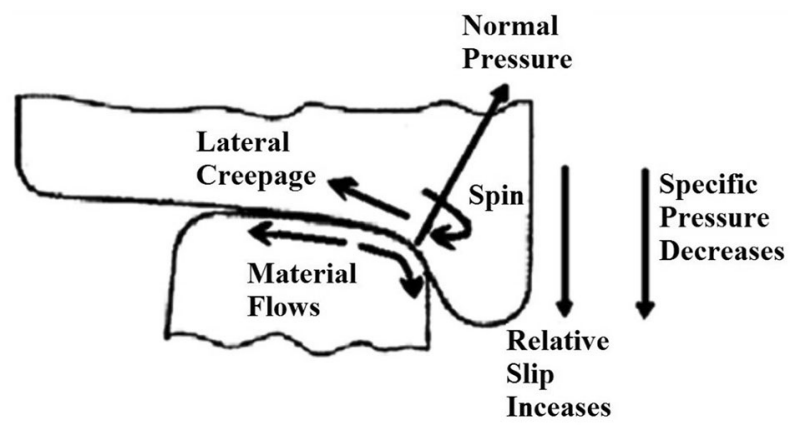

Fig. 5 Wear model of flange contact

case, the inner side wear of the rail is not considerable. Due to the reduced contact stress, there is always the possibility of a thin layer of lubricant to prevent direct contact between wheel and rail that is a contact of metal with metal. In this contact, the wear rate remains constant throughout the service life. In addition, lubricating this contact mode reduces the creep force between the flange and the medial collateral to reduce the wear rate profile. Moreover, this contact type is more resistant to rolling contact fatigue of rail and wheel contact. This type of exposure is more resistant to indentation of rail and reduction in under surface rolling contact fatigue destructions in rail and wheel contact $[24,26]$.

\subsection{Contact Zone $\mathrm{C}$ (Between the End of the Crown Wheel and the Crown of the Rail)}

The contact may occur due to poor design of structures and in this case arise against the wheel flange contact with the internal side rails and removal from the line occurs. In this area, one of the two modes is possible [24]:

- High contact stresses due to the contact of the end of the crown wheel with the rails.

- Completion of the contact before the virtual wheel flange meets the end of the crown.

\section{Wear in a Variety of Rail Lines}

\subsection{Wear in Straight Lines}

Rolling friction of the wheels and the rails on the side of the cap causes wear in rails in straight lines and can make the most of this type of wear vertical resulting in reduction in rail height. In this case, the amount of wear on rail transit burden depends on the weight of the vehicle, while passing the rail and the weight of the load at the contact of wheels and rails is transferred to the rails. The large amount of stress that exceeds the strength of steel rails results in the deformation and plastic strain to a limited depth below the top surface of the rails [5].

\subsection{Wear in Curved Lines}

The most important part of the wheel to be affected by wear is the flange area, which is used to maintain dynamic stability of the vehicle and prevent its removal from the line. According to published reports from wear situation on the London Underground, the factors affecting the deterioration flange, the most effective agent, are moving in severe arches [27]. The severity of wear is to the extent that the flange wear is reduced 16-21 times only by using appropriate lubrication in arches.

In the arches, particularly in the outer rail of the arch and other than vertical abrasion, sidelong wear can also be seen that depends on the amount of traffic and the radius of the arch in addition to the width and speed of trains. This type of wear is usually seen in less than 500-m-radius arches. In examining the causes of this type of wear, it can be said that the wheels of the train input forces when they pass through an arch on a line, which includes the centrifugal force and the forces of the arch itself, and it must be taken into consideration that the centrifugal forces are caused by the transverse slope. If the transverse slope of curved lines is less and line width is more than a limit value, the wear rate decreases [9]. In some lines, transverse slope is practically considered more than the balanced amount which intends to help move trains pass faster. In this case, the internal rail has a greater burden to bear, causing more wear and a greater chance of breaking, as it appears with a vertical slit in the crown. If the slope width is less than the balance, the outer rails bear greater loads and rail rolling risk or the wheel coming off the rail is increased [5]. 


\section{Wear Mechanisms}

\subsection{Abrasive Wear (Scratch)}

Abrasive wear occurs when a hard surface is rubbed against a soft surface and by penetration, causing a track on the soft surface. The special symbol to separate this from other types of wear is that there is no wear regarding tiny particles that cause the severe losses [28]. This type of wear is divided into two-object and three-object wear. In the two-object wear, there is a scratch on the surface and it only happens when a hard surface has slipping movement against a softer one and causes penetration and tracks, and leads to weight decreases in the softer one. The three-object type occurs when an abrasive matter separates some particles from the interface between the slipping parts [29]. The presence of sand utilized to improve the adhesion and increase traction of locomotives can be seen as the main factor leading to grazing of locomotive wheels [30] (Fig. 6).

Abrasive wear occurs as follows by different mechanisms (Fig. 7).

The microplowing phenomenon is primarily seen on very soft surfaces. The key indicator for this mechanism is a strain in a relatively large area around the surface tracks. In this case, scratches on the soft body would not scrape off the material, and the material only move on the surface and is regularly stored as a bulge on both sides of the created groove. Transfer of microplowing mechanism to microcutting takes place when the hardness of the material is increased. If the hardness of the sliding surface increases more and more, the abrasive wear can transform to microcracking. In this mechanism, the particles are rubbed off due to the formation and growth phenomenon of a crack embedded in the grooves. Particles accumulated in slots around the abrasive surface move constantly that would lead to a microfatigue phenomenon [31].

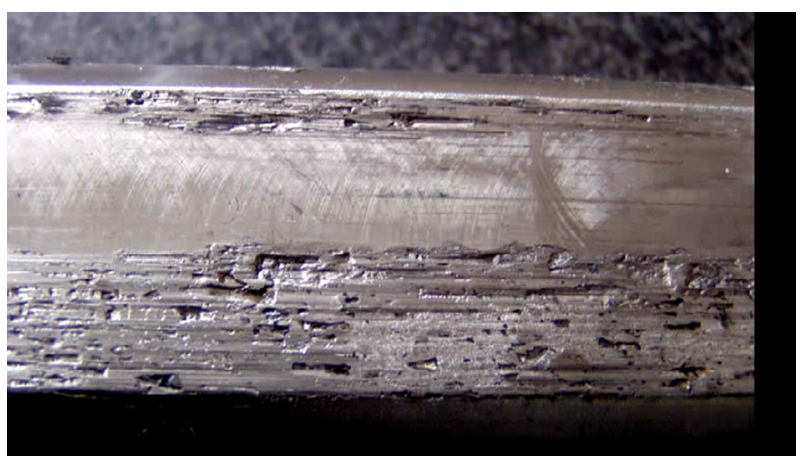

Fig. 6 Wear scratches on rails [30]

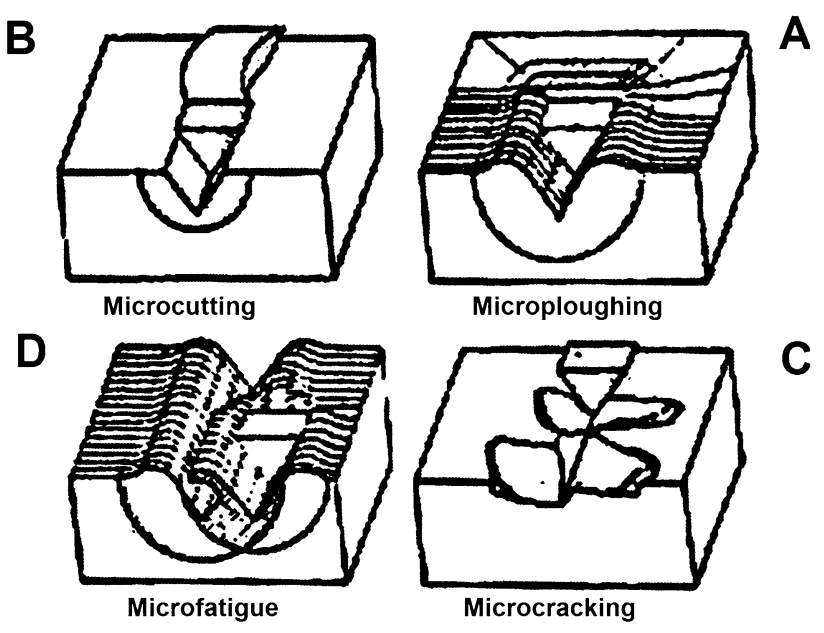

Fig. 7 Abrasive wear mechanisms: a fine plowings; b fine cuttings; c fine cracks; $\mathbf{d}$ microfatigue [32]

The rate of hardening, ductility of metal, homogeneous strain distribution and mechanical instability are the most important factors in the abrasive wear mechanism.

\subsection{Adhesive Wear}

Surfaces of engineering parts which are produced by different processes are not completely flat and have different non-homogeneities. As a result, contact of the engineering parts on the surface occurs at some scattered points which creates high stress around these points. This incident causes plastic deformation and local contacts on the surface. Adhesive wear occurs if there is local slip between two surfaces in the joints and, eventually, causes failure by the transfer of material from one surface to the other (Fig. 8). Adhesive wear mechanism is divided into two forms of moderate and severe decline in the rate of wear of the metal from the body and particle size [33]. The moderate form appears in straight lines and gentle arches, in which lubrication is not used. In this mode, a form of severe wear and lubrication in dry flanges occurs.

The tendency to form adhesive connections depends on the chemical and physical properties of the materials

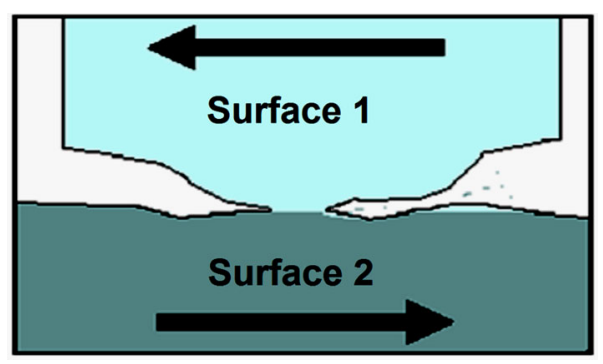

Fig. 8 Adhesive wear mechanism [34] 
involved, type and amount of load and surface properties such as pollution and the roughness [34].

Since the surface is rough and wavelike, the points of contact time are short-lived. This short period of time characterizes the slipping of a system and determines the thickness of the layer that is undergoing wear. Component life correlates directly with the contact of the sliding velocity and inversely correlates with the surface roughness. One of the main sources of energy dissipation in slipping is what should be done in the formation and breaking of molecular bonds that are in contact with two levels of slipping contact (Fig. 9). Molecular reactions lead to the formation of more or less strong connections to the so-called microseizure. Bodies involved rigidity, modulus of elasticity and other factors that determine the level of contact determine the type of stop.

The Archard wear equation to examine the phenomenon of adhesion is presented as follows:

$W_{\mathrm{ad}}=\frac{V}{L}=K \frac{F_{\mathrm{N}}}{H}$

In this relation, $W_{\mathrm{ad}}$ is wear rate (volume per unit of distance traveled worn sliding), $K$ coefficient of wear, $V$ worn volume, $L$ sliding distance, $F_{\mathrm{N}}$ vertical load and $H$ the hardness of the softer material. In this equation, hardness is considered as the only reason of wear as the feature of the material $K$ depends on the contact pressure levels and sliding speed of the two objects.

\subsection{Delamination Wear}

Delamination wear can cause microscopic wear. If the plastic deformation surface layer is prevented, the wear rate is greatly reduced. In this type of wear, the surface of material is thought to be separated by the process of wear [31]. Delamination wear occurs in three steps by plastic deformation, germination of cracks and crack propagation [28]. According to the delamination wear theory, the deformation of a plastic shape, crack formation and growth are created in a short depression of the surface that ultimately caused separation of sheets of wear particles.

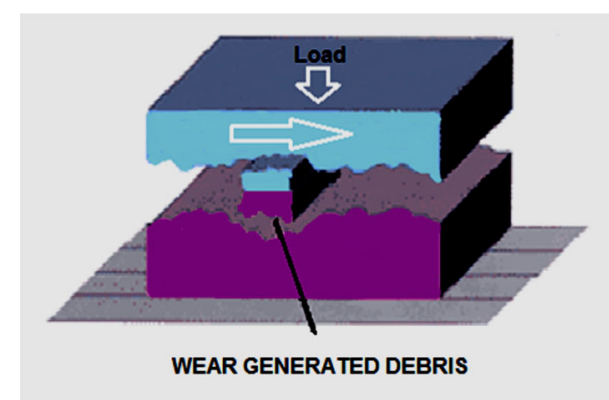

Fig. 9 Particles created from adhesive wear [34]
When the sliding surfaces are in contact with each other due to repeated loading, smoother surface is easily deformed. When this heterogeneity of the surfaces is modified, the surface is relatively become smooth [35].

Due to alternate loading of harder heterogeneity on the softer surface, plastic shear deformation is accumulated and some points are deformed at the surface and below the surface. This causes the creation of cracks below the surface. The plastic deformation causes it to expand and grows to the adjacent cracks and cavities. In locations with low strength, these cracks cut the surface from depth and wear particles appear as thin and long sheets. The thickness of wear particle formed depends on the growth of cracks in the surface and controlled vertical and tangential forces (friction). When a hard metal with a high elastic modulus contacts a soft metal with a lower elastic modulus, surface dislocations in the soft metal is driven into the interior, so hardworking is created under the layer of softer metal. Figure 10 shows an example of this type of wear on the wheel [30].

\subsection{Tribochemical Wear}

This type of wear on contact surfaces results from reactions with the environment. The surrounding environment can be in the state of gas or liquid. Wear layers are produced through a continuous separation process, and the reaction products of the reaction layer at the interface is seen in this type of wear. This means that the process of the abrasion of the surface layers of the products in chemical reactions begins and continues with the separation of them [28]. Tribochemical wear is greatly influenced by the surface layers and their properties that determine the resistance to separation. These properties include flexibility, strength and adhesion to the substrate. The tribochemical wear mechanism is shown in Fig. 11.

On one hand, abrasion-resistant materials used as additives for lubricants can lower metal to metal contact friction and therefore reduce adhesive wear; but on the other hand, the use of these substances leads to the formation of surface layers. As a result, the use of lubricants and

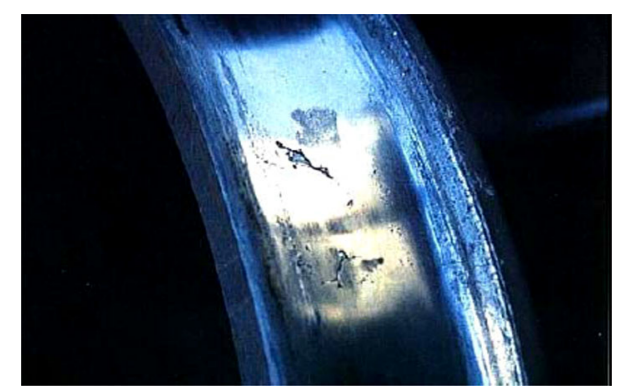

Fig. 10 Delamination wear of wheel [30] 
Fig. 11 Tribochemical wear mechanism [34]

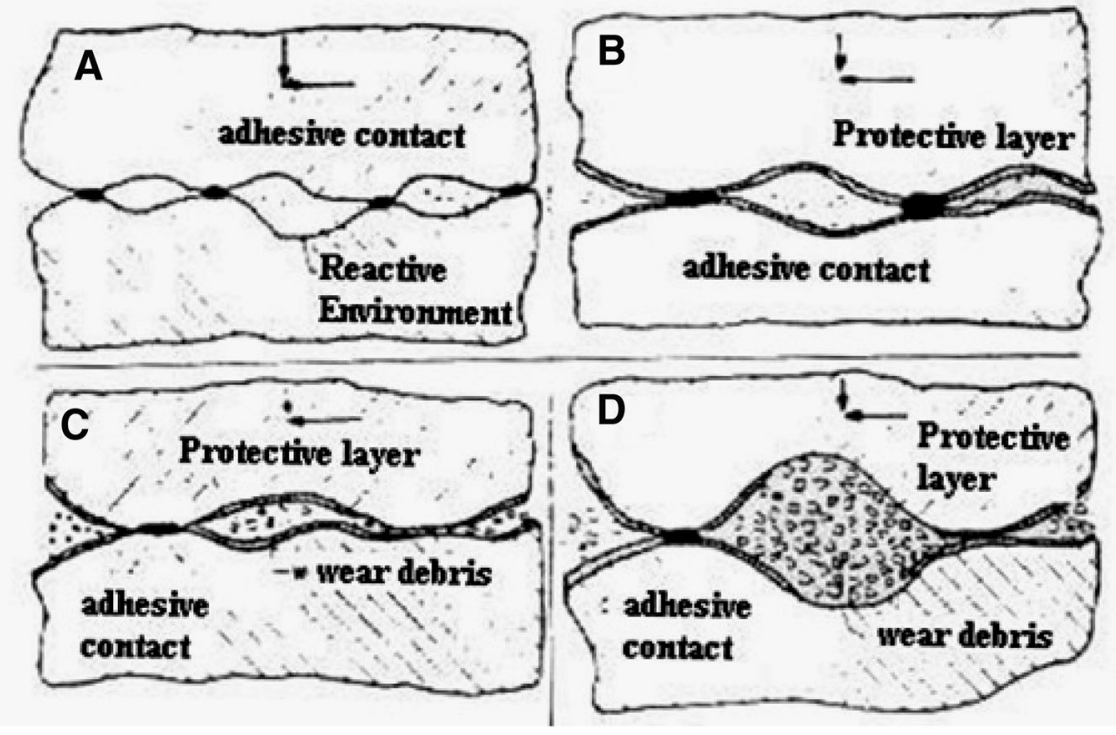

additives prevents a sharp deterioration due to the increased risk of adhesion [34].

Increased chemical activity levels happen by increasing the thickness of the protective layer. Therefore, the level of adhesive contact and eventually adhesive wear will be reduced. Wear of a thin surface layer leads to a wear reduction, by increasing the thickness of the brittle surface layers, which increases the tendency to crack. Chemical activity to minimize the amount of wear depends on the severity of the slip, contact pressure, temperature and surface quality. Tribochemical reactions which produce a harder surface layer can reduce wear, but on the other hand increases abrasive wear.

\subsection{Fretting Wear}

Fretting wear is caused when two surfaces would have tangential and oscillating movements under the applied loads with low relative amplitudes and the slip is caused by vibratory or cyclic stresses [36, 37]. This phenomenon is often associated with corrosion and oxidation. As shown in Fig. 12, observed by electron microscopy, fretting wear mechanisms are evident in four stages [38]:

A. Adhesion and metal wear particles (Adhesive wear).

B. Creation of wear particles by mechanical-chemical effect. Mechanical action causes breaks off the oxide film and cleans the surface and strains of the metal, which is due to be active in the next half cycle, and the presence of this level in atmosphere causes oxidation (tribochemical wear).

C. Production of a uniform particle abrasion by fatigue (fatigue surface wear).
D. Wear oxide particles are created from the process as an abrasive powder and result in the ongoing destruction of the surface (abrasive wear).

Among the factors affecting the deterioration due to fretting are the number of cycles, the range of motion, force, frequency, temperature, hardness, lubrication and atmospheric environment.

\subsection{Surface Fatigue Wear}

Surface fatigue is a phenomenon caused as a result of the effects of stress fluctuations under the condition which two solid materials have sliding contact [38]. This kind of wear is created with the formation of cracks and separation of material from the surface due to use of the repetitive alternating forces [36, 37]. The rotating contact or slipping and also alternative impact can cause cycle stresses on the surface. Despite the pollution-free lubricant, adhesive and abrasive wear is not created, but surface fatigue causes destruction of parts due to the alternative loading caused by the reaction of the components, and the destruction may begin with a defect or surface cracks [39]. Figure 13 shows the schematic of the crack formation process.

This kind of wear is observed in smooth lines and arches with proper lubrication. The wear particles stick to the surface of the wheel and the rail and they don't separate until they are removed like sheets of contact surfaces (Fig. 14). The reason of this kind of wear is the separation of particles which were from the plastically deformed. One of the most useful ways to overcome this mode is suitable grinding of rails [40]. 
Fig. 12 Various stages of fretting wear, $\mathbf{a}$ accumulation of trapped particles in the space between high spots,

b integration of contact areas into a united area, $\mathbf{c}$ spalling of particles into the adjoining depressed regions, $\mathbf{d}$ formation of the curved zone in the middle of the contact area caused by the intense wear process

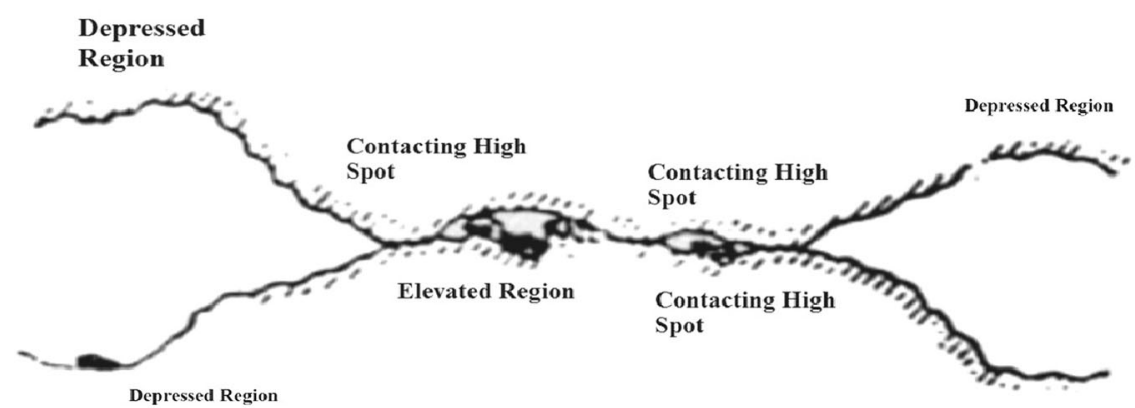

A
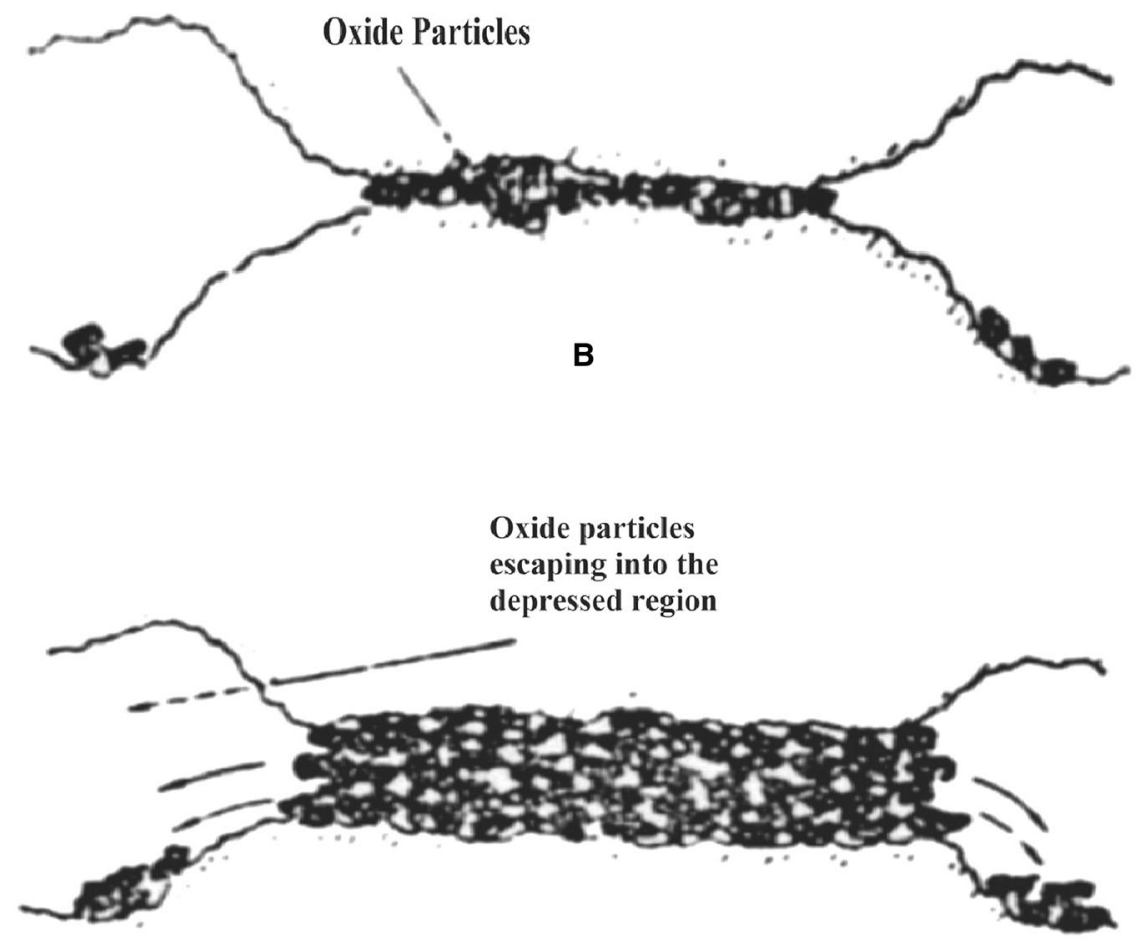

C

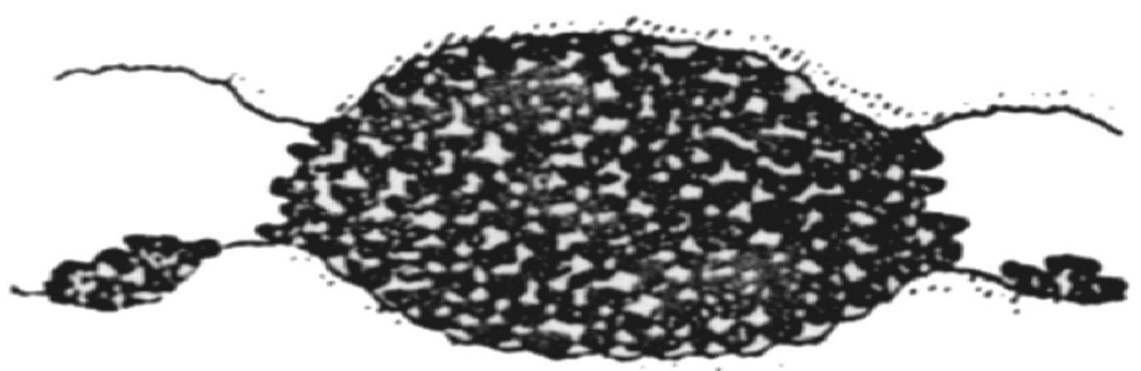

D 
Fig. 13 Formation and propagation of cracks in the surface fatigue mechanism [39]

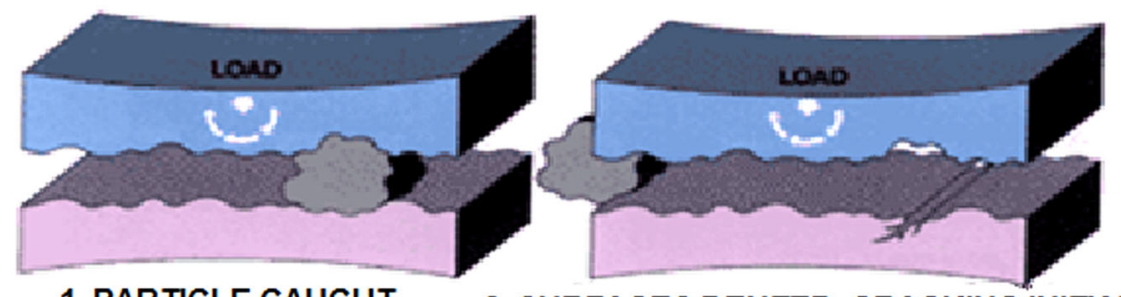

1. PARTICLE CAUGHT

2. SURFACES DENTED, CRACKING INITIATED

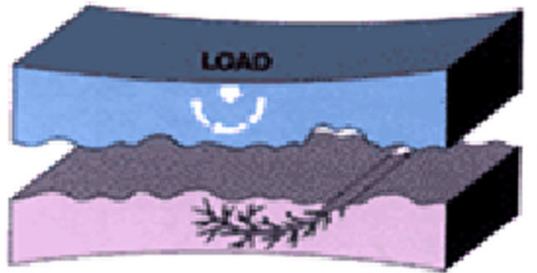

3. AFTER "N" FATIGUE CYCLES, CRACKS SPREAD

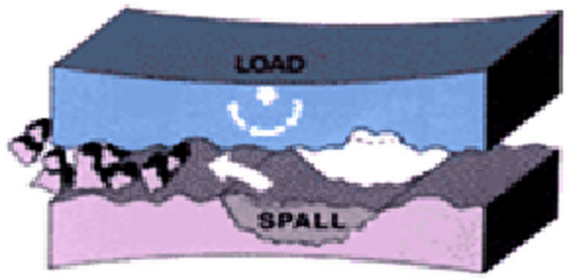

\section{SURFACE FAILS, PARTICLES RELEASED}

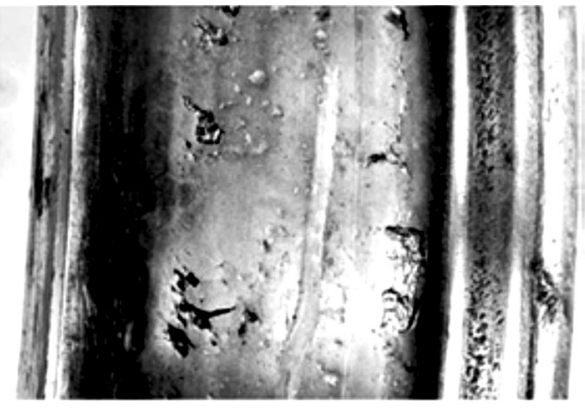

Fig. 14 Surface fatigue wear on the wheel [40]

\subsection{Impact Wear}

Impact wear can be produced when a solid surface is continuously in contact with another solid surface. The wear mechanism are related to [28]:

- Material used: for example, thermal wear is likely to occur in polymers.

- Contact tension range: such as contact fatigue in comparison with corrosive fatigue

- Speed: increasing speed makes corrosive wear with low stress to the adhesive wear.

- Type of loading: for example, tangential load causes a slip or vertical causes impact.

\section{Parameters on the Wheel and Rail Wear}

Theory and practice of management in terms of wheel and rail contact during the past 20 years are to increase the life of wheel and track and improve their adaptability and the use of greater axial loads. Wheels combined with high- strength steel-polished rail profiles lower wear and improve lubrication. Various effects such as difficulty of body contact, coefficient of friction, changes in lateral and longitudinal creep and wear volume are effective. Due to the lack of accurate predictions of actions and reactions created between rail and wheel (adhesion between the rail and the wheels, the alignment of rails and wheels together, rail level pollution, ambient temperature, humidity, hard surfaces, railways, the quality of the natural and physical infrastructure and other factors), determination of the level of each factor on the force between the rail and wheel wear rate is difficult [5].

\subsection{Effects of Friction Coefficient}

The coefficient of friction depends on factors such as the microstructure of materials, load, quality levels and how it is the measured. Contact zone temperature is also significantly affected by friction. By increasing temperature, the mechanical properties of the lubricant have changed, the speed of oxidation increased and there is even the possibility of fuzzy degradation. So, all of these affect the amount of friction [31].

Rail and wheel and glide wheel and the locomotive traction are reduced, to prevent the infiltration of lubricant when rolling solid lubricants can be used that have high viscosity [41, 42] (Fig. 15).

\subsection{Effects of Adhesion Coefficient}

The maximum force applied by the wheel and rail mechanism depends on two parameters of the coefficient of friction at the contact surface and axial load. Adhesion or adhesion coefficient is defined as the maximum tensile 


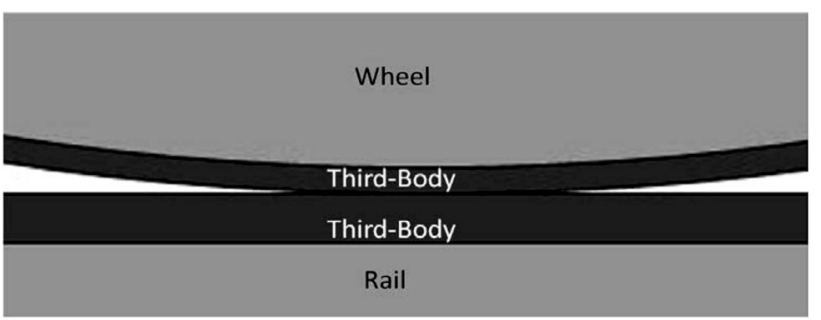

Fig. 15 Lubricating rails to reduce surface friction coefficient [42]

strength in the wheel rim to the vertical load of the wheel and is defined in the contact area at the slip moment [33].

When the wheel spins under the influence of torque to move the tub (Traction effort), stagnation or slip phenomenon occurs. The goal is to achieve maximum coefficient of adhesion at high-speed insertion. This is usually done through the use of special materials in the contact area between the wheel and rail in addition to increase in the coefficient of friction [40].

The coefficient of adhesion depends on several factors such as creep in the contact area of wheels and rails, the surface profile of wheels and rails, wheel and vehicle speed rail, rail vehicle dynamics and characteristics of the traction system. Surface conditions of the line such as the presence of oil and water can be effective in reducing the coefficient of friction and cause a decrease in the coefficient of adhesion. For this purpose, sand particles are used to overcome this defect. General parameters that affect the coefficient of adhesion are [40]:

- Locomotive weight and axle load distribution on the drive shaft

- Speed

- Dimensional changes due to abrasion wheel

- Surface rail

- Curved line (straight line or arc)

- Steel wheels and rails

In addition, the negative effects of excessive adhesion factor include [43]:

- Abnormal and uncontrollable movement of the wheels in the arches

- Creation and development of cracks in rails

- Increase wheel wear

- Unwelcome noise and high arches

Different materials are now used to increase or decrease the friction to control the adhesion in rail transport, but there should be a lot of care about the use of these materials because some of them (especially materials that are used to reduce friction) have a relatively permanent effect that will only be eliminated by machining the surface of the rails.

\section{Conclusion}

One of the most critical and the most important problems of the railway industry is wear. In some cases, the wheel and rail wear is severe enough to spread to the adjacent rail profiles and damage the adjacent rail lines. It is noteworthy that the most destructive factor causing wheel and rail wear, which can be significant and have negative consequences, is dynamic instability which is common to rail vehicles. Hence, different types of wear mechanisms, causes and the importance of preventing the emergence of any of them are fully examined. Identification of and reduction in the phenomenon, which can create the permanent deformation of the rails, reduce wheel life, reduce safety, increase maintenance time of the vehicle and thus reduce productivity and increase costs, require a good understanding of the wear mechanisms of the wheel and rail. This study investigated the phenomenon of the interaction between wheel and rail wear, including influencing factors such as friction, adhesion, abrasive and ways to reduce these phenomena in contact such as lubrication were also introduced.

Open Access This article is distributed under the terms of the Creative Commons Attribution 4.0 International License (http://crea tivecommons.org/licenses/by/4.0/), which permits unrestricted use, distribution, and reproduction in any medium, provided you give appropriate credit to the original author(s) and the source, provide a link to the Creative Commons license, and indicate if changes were made.

\section{References}

1. Jendel T (2002) Prediction of wheel profile wear-comparison with field measurements. Wear 253:89-99

2. Kumar S (2007) The investigation of derailment. Indian Railways Institute of Civil Engineering, Pune

3. Soleimani H (2015) A study and comparison of different methods for wheel-rail wear measurement and proposing an applicable local method. MS Thesis, Ferdowsi University of Mashhad, School of Mechanical Engineering, Mashhad, Iran

4. Soleimani H, Nejad RM, Moavenian M (2016) Common failures in wheel and rail and different methods of measuring their profiles. In: Proceedings of the 1st international conference on mechanical and aerospace engineering, Iran

5. Zakeri JA, Ghorbani V (2011) Investigation on dynamic behavior of railway track in transition zone. J Mech Sci Technol 25(2):287-292

6. Mohammadzadeh S, Ghahremani S (2012) Estimation of train derailment probability using rail profile alterations. Struct Infrastruct Eng Mainten Manag Life Cycle Des Perform 8(11):1034-1053

7. Mahlooji V, Ghazavi MR (2014) Railway vehicle derailment in curve due to wear. Modares Mech Eng 14(8):199-208

8. Mir Majidi SMH, Ohadi A, Rezvani MA. Wear of wheel flange and its effects on Tehran's subway trains, Tehran. In: 10th conference and 3rd exhibition of railway transportation achievements 
9. D'Acunto M (2003) Wear and diffusive processes. Tribol Int 36:553-558

10. Zakharov SM, Zharov I, Komarovski I (1999) Tribological aspects of rail/wheel interface. In: International heavy haul railway conference, St. Louis

11. Zakharov SM, Zharov IA (2005) Criteria of bogie performance and wheel/rail wear prediction based on wayside measurements. Wear 258(7):1135-1141

12. Carter FW (1926) On the action of a locomotive driving wheel. Proc R Soc Lond A Math Phys Eng Sci 112(760):151-157

13. Vermeulen PJ, Johnson KL (1964) Contact of nonspherical bodies transmitting tangential forces. J Appl Mech 31:338-340

14. Garg VK, Dukkipati RV (1984) Dynamics of railway vehicle systems. Academic Press, Ontorio

15. Kalker JJ (1967) On the rolling contact of two elastic bodies in the presence of dry friction. Doctoral Thesis, TU Delft, Delft

16. Kalker JJ (1987) Wheel-rail wear calculations with the program contact. Delft University of Technology, Delft

17. Zhai WM, Cai CB, Guo SZ (1996) Coupling model of vertical and lateral vehicle/track interaction. Veh Syst Dyn Int J Veh Mech Mobil 26(1):61-79

18. Telliskivi T, Olofsson U (2004) Wheel-rail wear simulation. Wear 257(11):1145-1153

19. Diana G, Bruni S, Braghin F (2005) Wheel-rail contact: wear effects on vehicle dynamic behavior. Dipartimento di Meccanica, Politecnico di Milano, Milan

20. Braghin F, Lewis R (2006) A mathematical model to predict railway wheel profile evolution due to wear. Wear 261:1253-1264

21. Ranjbar M, Ghazavi MR (2013) Bifurcation analysis of highspeed railway vehicle in a curve. AMAE Int J Prod Ind Eng 4(1):13-17

22. Pombo J (2012) Application of a computational tool to study the influence of worn wheels on railway vehicle dynamics. J Softw Eng Appl 5:51-61

23. Molatefi H, Firouzabadi Z (2011) Analyzing the interaction between wheel profile S1002 and Iran rail profiles to investigate wheel-rail wear and wheelset behavior. $J$ Transp Eng 2(48):363-374

24. Serajian R (2005) Comparison of contact theories of wheel and rail. The School of Railway Engineering, Iran University of Science \& Technology, Tehran

25. Salehi M, Farahi G (2012) Stress analysis worn profiles based on Hertz theory. In: Twentieth annual conference of mechanical engineering, Tehran

26. Tournay H, Giani J (1995) Rail/wheel interaction: multidisciplinary practices developed in South Africa. In: Railway engineering conference, Melbourne, Australia
27. B. G. Engineering, The impact of MMU research on the optimisation of railway vehicle-track interaction. Manchester Metropolitan University

28. Mollasalmani M, Rezvani MA, Shahverdi H (2013) Filed study on the effect of lubrication on controlling wheel flange wear in 6-axle locomotive (type DF8BI). In: The 3rd international conference on recent advances in railway engineering, Tehran

29. Olofssona U, Zhua Y, Abbasia S, Lewi R, Lewis S (2013) Tribology of the wheel-rail contact-aspects of wear, particle emission and adhesion. Veh Syst Dyn Int J Veh Mech Mobil (Special Issue: State of Art Papers of the 23nd IAVSD)

30. Kaneharaa H, Fujioka T (2002) Measuring rail/wheel contact points of running railway vehicles. Wear 253(1-2):275-283

31. Jin X, Zhang J (2001) A complementary principle of elastic bodies of arbitrary geometry in rolling contact. Comput Struct 79:2635-2644

32. Chevaliera L, Cloupet S, Quillien M (2006) Friction and wear during twin-disc experiments under ambient and cryogenic conditions. Tribol Int 39(11):1376-1387

33. Jahed H, Nasr A, Eshraghi A (2004) Parameters influencing wear in Iranian state railways. In: Proceedings of the 7th international conference of rail ways, Sharif University, Tehran

34. Jamison WE (1981) Wear test results on eight samples of rail from FAST. Tribology Materials Development Corporation

35. Archard JF (1953) Contact and rubbing of flat surfaces. J Appl Phys 24(8):981-988

36. Zheng J, Luo J, Mo J, Peng J, Jin X (2010) Fretting wear behaviors of a railway axle steel. Tribol Int 43(5-6):906-911

37. Waterhouse R (1984) Fretting wear. Wear 100(1-3):107-118

38. Bhushan B (1980) Review of experimental techniques in EHDlubricated contacts. DOE Tech. Rep. No. AT80DO69, SKF Industries, INC., King of Prussia, PA

39. Matsumoto A, Sato Y, Ono H, Wang Y, Yamamoto M, Tanimoto M, Oka Y (2002) Creep force characteristics between rail and when on scaled model. Wear 253(1-2):199-203

40. Ahlstrom J, Karlsson B (1999) Microstructural evaluation and interpretation of the mechanically and thermally affected zone under railway wheel flats. Wear 232:1-14

41. Cantizano A, Carnicero A, Zavarise G (2002) Numerical simulation of wear mechanism maps. Comput Mater Sci 25:54-60

42. Zhu Y (2013) Adhesion in the wheel-rail contact. Doctoral Thesis, Department of Machine Design, Royal Institute of Technology, Stockholm, 2013

43. Yazykov V, Pogorelov D, Mikhalchenko G (2004) Railway vehicle simulation using non-elliptical wheel-rail contact model. In: Mechanics of 21st century-ICTAM04 proceedings, Warsaw, Poland 